\title{
Experiences from a Quantum Leap Improvement in Turbine Manufacturing
}

\author{
Findings in a research project in cooperation between Kvaerner Energy AS and \\ SINTEF
}

Ivar Bliko, Stefan Kowerich and Pal Paulik

SINTEF Industrial Management: SINTEF Industrial Management: Kvaerner Energy

Key words: 5-axis milling, plunge cutting, Hydro Power Turbines, Enterprise development

Abstract: This paper discusses experiences from a research project aiming at the improvement of the machining process for Hydro Power Plant Turbines. Both technical results and experiences from the process to achieve these results are expressed. A number of improvement features regarding 5-axis machining of sculptured surfaces are discussed. Major findings are pointed out as the lack of suitable functions in the $\mathrm{CAD} / \mathrm{CAM}$ system to cope with the challenges of this specialised product. Improved machining strategies as "Parallel Cut", "Constant Gap Strategy", and "Multi-axis Plunge Cutting" are introduced. The outcome of the project was a new method for manufacturing of turbines. Based on the experience in the development project, reflections regarding organisational mechanisms for Quantum Leap Improvement are discussed.

\section{INTRODUCTION}

Kvaerner ASA is one of the largest industrial enterprises in Norway with 80000 employees world-wide, with Kvaerner Energy a.s as a subsidiary with 3675 employees worldwide.

The main product of Kvaerner Energy is complete hydropower plants, and the first hydropower turbines have been manufactured already in the last century. Since then Kvaerner has developed the manufacturing process of hydropower turbines continuously.

The last major change of the production process was in the beginning of the 1990s, where 5-axis milling replaced turning and 3-axis milling as the main technology. The consequence was a significantly higher quality of the turbines, but the production costs increased as well.

To meet the challenges of the future, producing high quality turbines at lower costs, Kvaerner understood that it was necessary to increase productivity further. The goal was not to become just as good as the competitors, but to become better.

Based on this situation, a project was carried through in the period from the end of 1995 to early in 1997 that focussed on the manufacturing of the runners for hydropower turbines. The name of the project was "Process Optimised Creation and Machining of Complex Geometry in 5-axis Machining Environment (PROFRAK)" and the Norwegian Research Council supported it. [1]

The goals of the project were:

- Modelling time: $50 \%$ reduction

- NC-programming time: $50 \%$ reduction

- Machining time: $20 \%$ reduction

Different departments at SINTEF and a Norwegian consultant company, Kongsberg 3D Partner, were engaged in this project.

This paper presents the main results of this project. The first chapter deals with the successful implementation of improvement measures in an early stage of the project, where the results were achieved by following a more traditional approach. The second chapter describes a break-through based on a change of the manufacturing process (the quantum leap improvement), and the last chapter rounds off the paper with some reflections about the reasons for the success.

The original version of this chapter was revised: The copyright line was incorrect. This has been corrected. The Erratum to this chapter is available at DOI: 10.1007/978-0-387-35392-0_40 


\section{THE TRADITIONAL APPROACH}

What is the usual proceeding of a project when two research engineers enter an industrial company?

They start with an analysis phase, identify areas of improvement, work out measures of improvement, implement the measures, and evaluate the results. The whole procedure is controlled by a detailed plan.

So did we.

\subsection{Analysis phase}

The production of Power Plant Turbines involves a lot of people. To get a brief understanding of sub-processes involved, departments dealing with hydrodynamics, design, construction, programming, machining, grinding, assembling and welding were visited. A lot of time was spent in the workshop to get an impression of how the production process elapsed.

The turbine runner has an impossible shape. The inner geometry is closed by the housing, and no method has been developed for machining a geometry of this kind and this size in one piece. Therefore, the production process until now has been based on a splitting of the runner into separate parts (crown, band, and vanes), and assembly of each individual part after machining (figure 1). The weight of the castings is up to 30 tons, and a complete assembled runner weighs up to 100 tons.

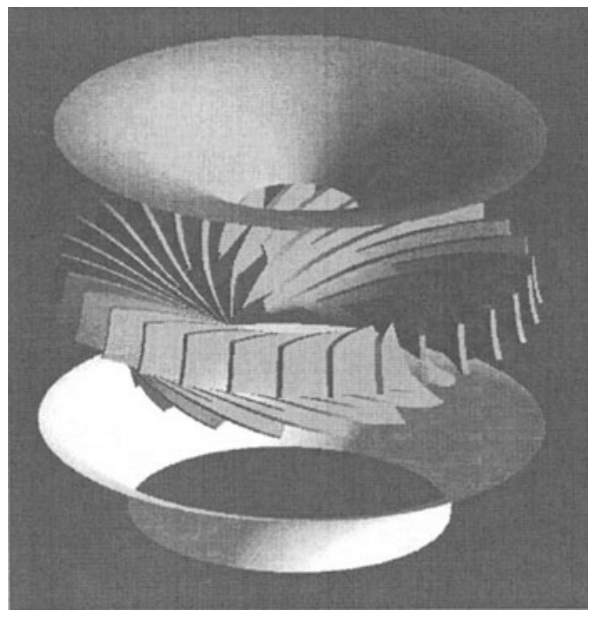

Figure 1. Exploded view of the turbine

Crown and band consist of a surface of revolution as the base geometry, with additional stubs where the vanes are welded on. The shape of the vanes is a sculptured surface formed according to hydrodynamic laws.

At the time we started the project, each of the main components was manufactured by its own production process. Crown and band were cast, machined, and ground, the vanes were cut from steel plates, pressed into shape, machined, and ground. At last, all components were assembled and welded. The workflow of the production processes is shown in figure 2 .

Since the focus of the project was to optimise the machining process of crown, band, and vanes, we analysed the different machining operations and came to significant observations. 
The machining operations for crown and band could be classified into three main sections:

- machining of the surface area between the stubs

- machining of the side of the stubs

- machining of the fillet between stubs and surface of revolution

All operations were performed using simultaneous 5-axis-milling. The vanes were machined using 3-axis-milling as the main technology.

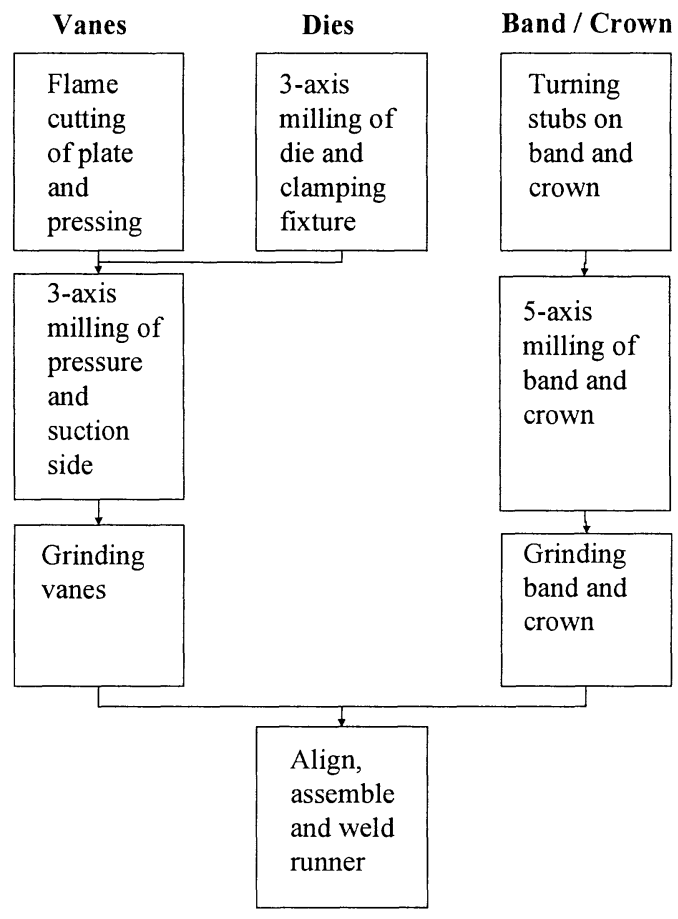

Figure 2. Manufacturing workflow of the turbine runner

\subsection{Problem identification}

At the end of the analysis phase we had some ideas of areas where we possibly could contribute with a certain amount of improvement. But we were anything but sure that solving these problems would result in the improvement that was defined in the project goals. At that stage we didn't know where the key to the quantum leap was.

The toolpath pattern for the machining of the surface area between the stubs was suboptimal. As shown in figure 3, the machining pattern followed the parametrical lines of the surface. This resulted in efficient machining just at the beginning of each cut, and decreasing removal rate along the tool path. In addition, to avoid conventional cutting, the tool was moved in air back to the outside, which increased the amount of idle cutting.

The machining of the fillet between the stubs and the surface of revolution was inefficient because of the use of a ballnose-cutter (Figure 5, right side).

The use of 3-axis-milling for the machining of the vanes seemed to be obsolete, since the company used simultaneous 5-axis-milling for the machining of the other components. 
The reason for the sub-optimal operations seemed to be a lack of functionality of the CAD/CAM-system. Ideas for improved operations, i.e. improved machining patterns and more efficient tools, existed at the company, but there has not been suitable functionality in the $\mathrm{CAD} / \mathrm{CAM}$-system to implement them in real production. It turned out to be the main purpose of the project to define improved machining operations, and to find out, how to program them using a commercial CAD/CAM-system.

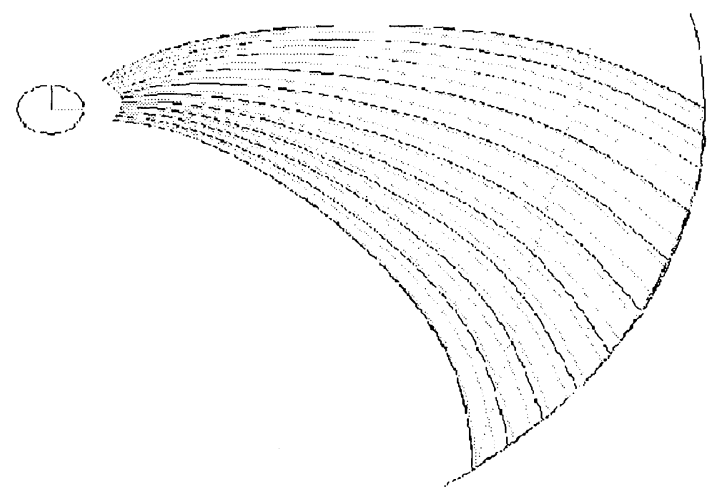

Figure 3. Isoparametric toolpath

\subsection{Measurement of improvement}

Already at an early stage in the project, ideas were discussed, and new machining strategies were sketched. We had a subconscious feeling that a successful implementation of these ideas would lead to some improvement. But how was it possible to implement these ideas, how to generate the toolpaths?

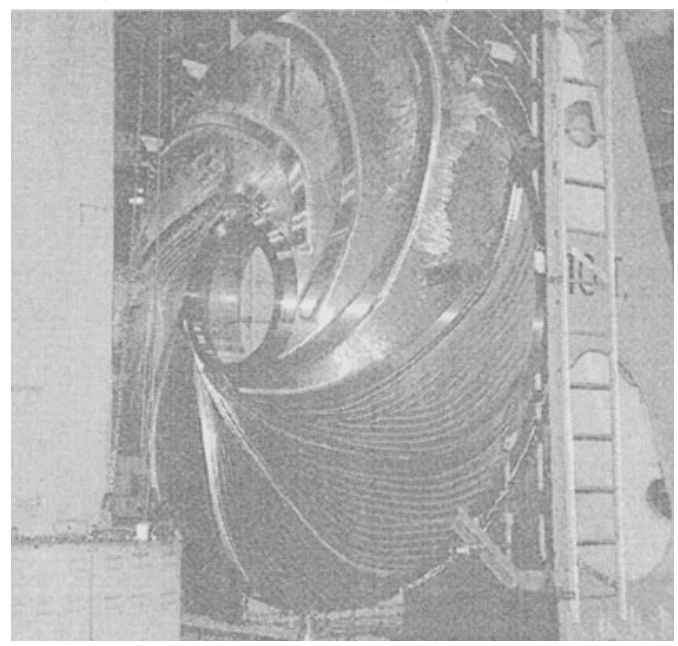

Figure 4. Parallel cutting strategy 
The main contribution to a drastically improved machining of crown and band was the change of the machining pattern for the surface area between the stubs. To improve the utilisation of the tool, the new toolpath pattern did not follow the parametrical lines of the surface, but curves with equal distance. This machining pattern allowed almost constant material removal rate, and reduced the amount of machining air by moving the tool both inward and outward. Figure 4 illustrates the resulting pattern.

The pattern was realised not by using the standard functions of the CAD/CAM-system for machining of surface area, but by manually modelling the machining pattern by a set of curves, and using the curves as a guide for the tool motions.

Today we know that also this machining pattern is not optimal. A lot of research has been done on this subject ([2], [3], .., [12]), but the results have not been implemented in commercial CAD/CAM-systems.

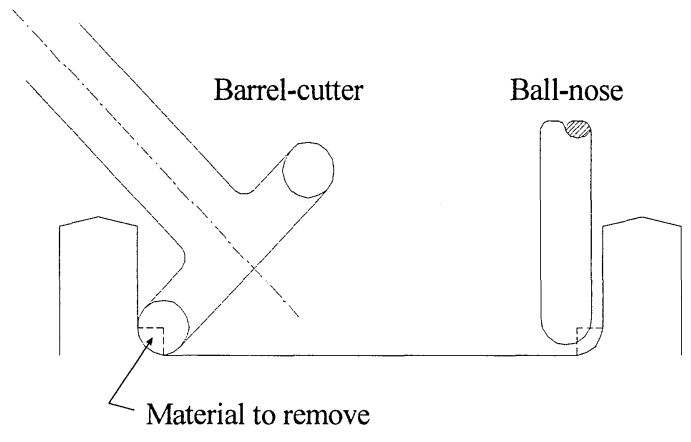

Figure 5. Barrel cutter for machining of fillets

Another important contribution to the improved machining was the replacement of the ballnose-cutter with a barrel-cutter for the machining of the fillet. By using a barrel-cutter whose barrel-radius is equal to the radius of the fillet, the time for machining the fillet was reduced to less than half the time needed when the ballnose-cutter was used. Figure 5 shows the principle of the machining operation.

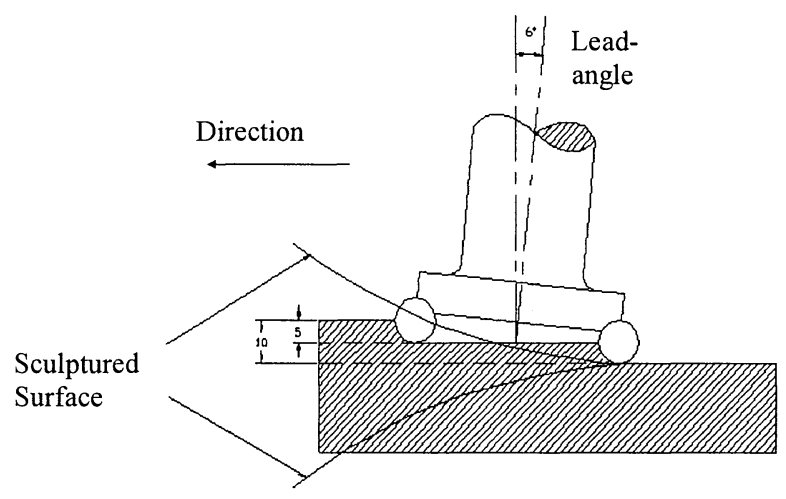

Figure 6. Constant Gap strategy 
The third improved machining operation that we tried to implement in production, was the machining with negative lead angle, also called the machining with constant gap. Figure 6 shows the principle.

In conventional simultaneous 5-axis-milling, the tool is tilted in the direction of movement. Recent research ([2]) shows that tilting the tool backwards, i.e. against the direction of movement, increases the stability of machining, and thus increases the achievable feedrate. In addition, by using both the forward and backward edge of the cutting inserts, the material removal rate can be increased by 40 to $50 \%$, as shown in the figure above. To achieve this, the gap between the inserts in front and the final surface has to be optimal. If the gap is bigger than the maximum cut depth of the inserts at the back of the tool, the will break. On the other hand, the gap has to be as big as possible to utilise the full potential of the method. The use of this machining method on sculptured surfaces requires the control of the tool axis in a way that renders an optimal gap between the inserts in front and the final surface. This control strategy is not available in commercial CAD/CAM-system, thus this machining method was not implemented in real production, even if a test of the method was successful and confirmed the results of the above mentioned research work.

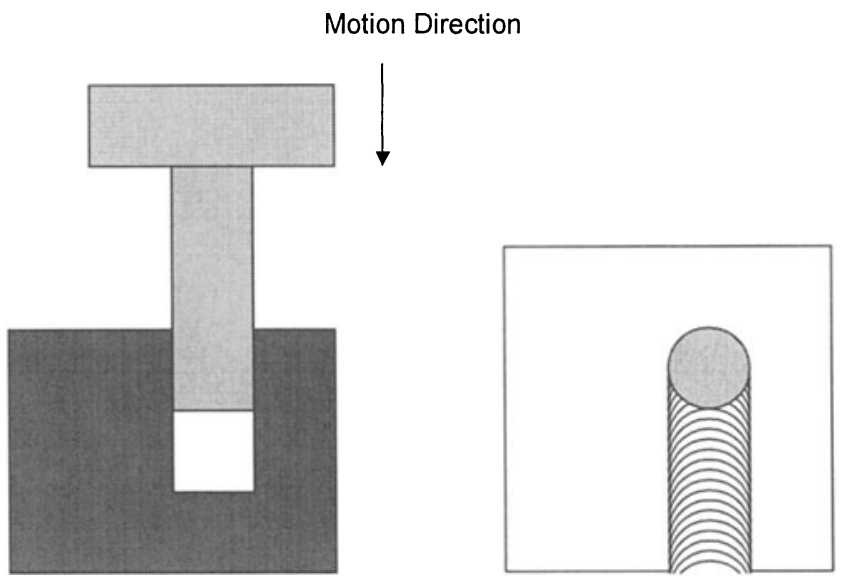

Figure 7. Plunge cutting

The final machining method that we want to present in this paper is 5-axis plunge cutting.

Conventional milling operations move the milling tool in a radial way, introducing radial forces to the tool, resulting in a significant tool deflection. Plunge cutting operations move the tool along its axis, introducing mainly axial forces, reducing the tool deflection, and thus stabilising the milling process. Figure 7 shows the tool motions.

Figure 8 shows a typical plunge cutting tool, a flat end mill with a special type of inserts. The radial stepover distance is restricted to the length of the cutting edge of the inserts.

Plunge cutting is a suitable operation for machining with long tools in relation to their diameter. Tool manufacturers of special plunge cutting tools recommend plunge cutting for conditions where the tool length is up to 10 times its diameter. For difficult material groups such as stainless steel, it can be profitable to use the method for lower length/diameter relations.

5 -axis plunge cutting is the application of the method for machining of sculptured surfaces, utilising the full freedom of tool positioning and orientation provided by simultaneous 5-axis-milling. This is discussed in more detail later in this paper. 


\subsection{Results of the implementation of the measures of improvement}

We implemented those of the new machining strategies that were possible to implement in real production. The results exceeded our expectations. At the beginning of the project, nobody had believed that it was possible to achieve such results.

The improved machining operations described in the previous chapter, at least those that have been implemented in real production, resulted in a significant reduction of the machining time for crown, band and vanes. Depending on the shape of the particular components, the time reduction was typically between 50 and $75 \%$, which was much better than the expected goal of the project.

At that point it would have been normal to terminate the project. Nevertheless, we didn't. Why?

In contrast to usual research projects, the results were achieved consuming less time and money as planned. The question was what to do with the rest of the budget?

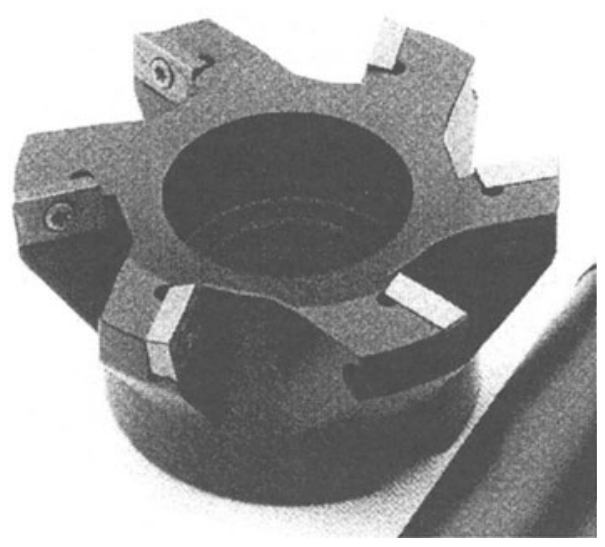

Figure 8. Tool for plunge cutting

\section{THE QUANTUM LEAP IMPROVEMENT}

There were some ideas that had followed us through the whole project, but they were classified as impossible to implement. One of the ideas was a production method based on splitting the geometry of the turbine runner in the middle of the vanes, i.e. machining one half of each vane together with crown and band, respectively.

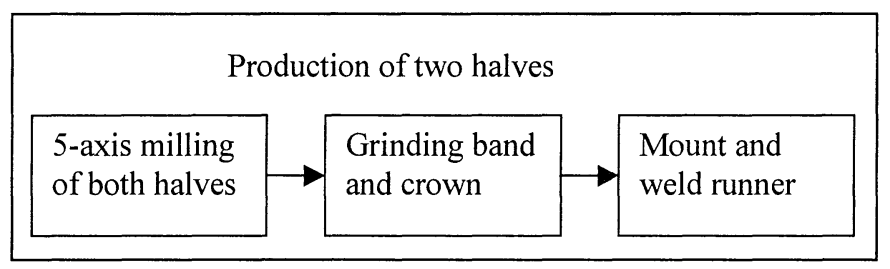

Figure 9. Workflow with new production process 
Picking up this idea and discussing its restrictions and advantages opened our eyes. All the improvements that we had achieved to this point were small compared with the overall potential of the new approach. It is true, the machining and NC-programming time for crown and band would increase significantly, but on the other hand, the whole production process of the vanes would be eliminated (compare figure 2 and figure 9). In addition, the welding process would be much easier.

But was it possible to produce a turbine runner in this way? We had a feeling that the enabling technology to achieve this goal was plunge cutting.

The central question at that point of the project was, if it would be possible to program 5 axis plunge cutting operations. The project resulted in that the answer to that question was yes, even if the resulting programming process was extremely time-consuming and error-prone, because commercial $\mathrm{CAD} / \mathrm{CAM}$-systems lack tailor-made functionality to program 5 -axis plunge cutting operations.

Machining of the runner of a turbine in two halves is a typical case for the use of 5-axis plunge cutting. Deep and narrow water canals require the use of long and slender tools, and the hydrodynamic shape of the turbines require the full freedom of simultaneous 5 -axismilling to be able to access these areas (figure 10).

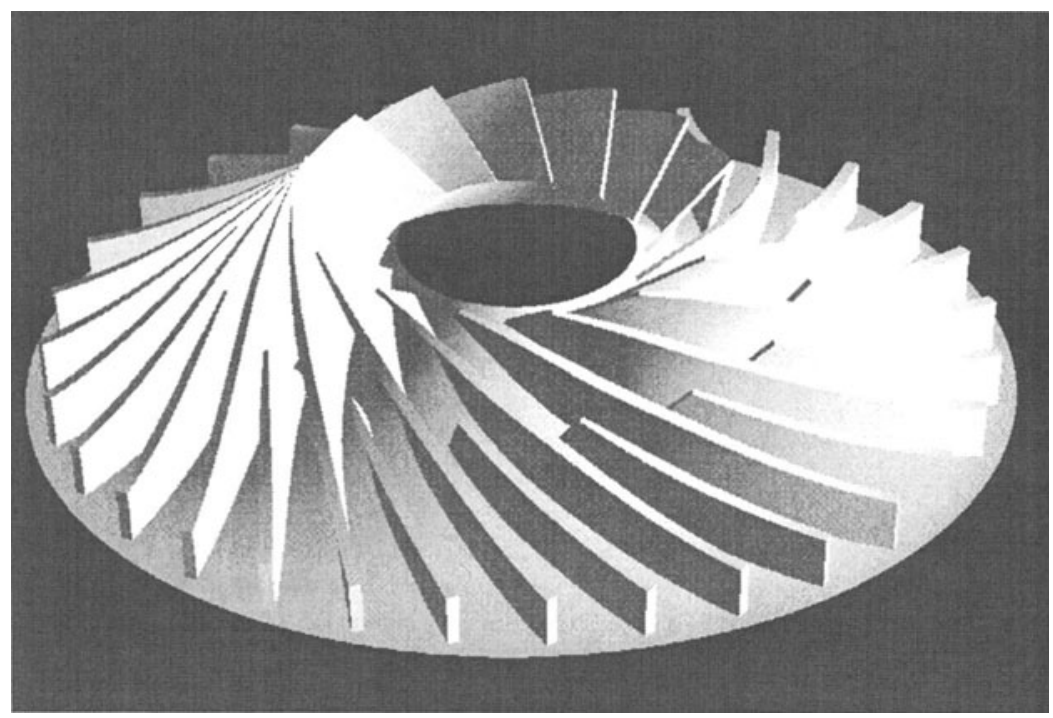

Figure 10. One half of the turbine

We identified two types of 5-axis plunge cutting, indexed and simultaneous 5-axis plunge cutting.

Indexed 5-axis plunge cutting is suitable for machining of the working allowance above a floor surface. The tool is moved to a point above the working allowance and then along its axis towards the floor surface. Its axis is oriented almost in the direction of the surface normal of the floor surface in the contact point, to minimise the amount of excess material (figure 11). We used the method to machine the surface area between the vanes. 


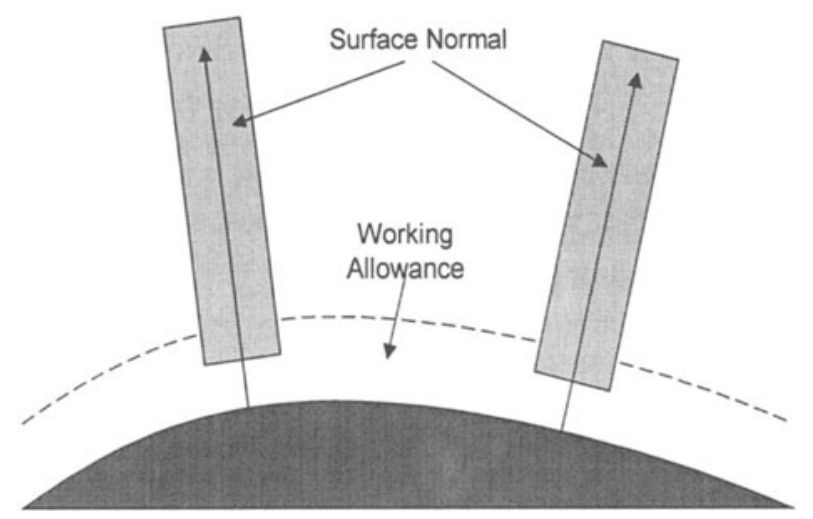

Figure 11. Indexed 5-axis plunge cutting

Simultaneous 5-axis plunge cutting has been used for the machining of the vanes themselves. As shown in figure 12 the tool is oriented in an angle near $90^{\circ}$ in relation to the surface normal, and the tool motion occurs approximately in the direction of the tool axis. The main condition of the tool motion is that the contact point follows the shape of the surface.

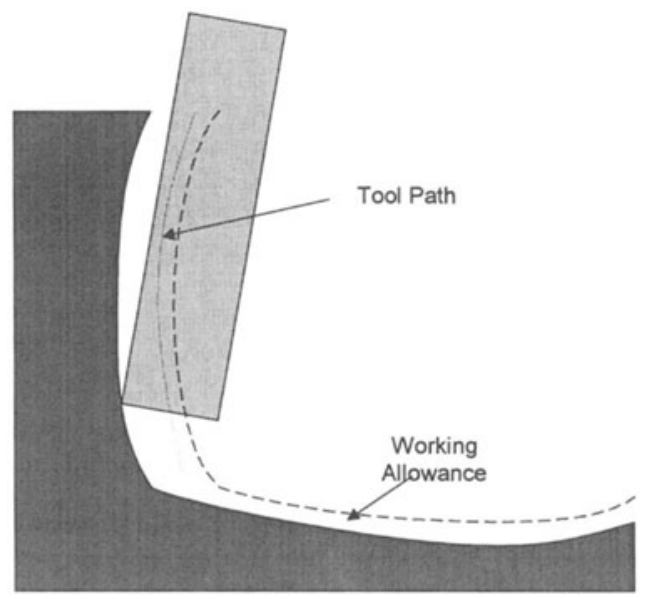

Figure 12. Simultaneous 5-axis plunge cutting

As mentioned initially, the generation of toolpaths for 5-axis plunge cutting is a timeconsuming process. The reason is the lack of tailor-made functionality in commercial $\mathrm{CAD} / \mathrm{CAM}$-systems. What are the aspects that make 5-axis plunge cutting so special?

The most critical aspect is related to the shape of the cutting tool. As mentioned earlier, the maximum radial stepover distance must not exceed the length of the cutting edge of the insert. The radial stepover distance is not constant along each cut because of the change of the tool axis for each cut. On convex parts of the surface, the stepover distance decreases, on concave parts, the stepover distance increases along the cut (see figure 11). There are no reliable mechanisms in the $\mathrm{CAD} / \mathrm{CAM}$-systems to make sure that the radial stepover distance is less than a max-value. 


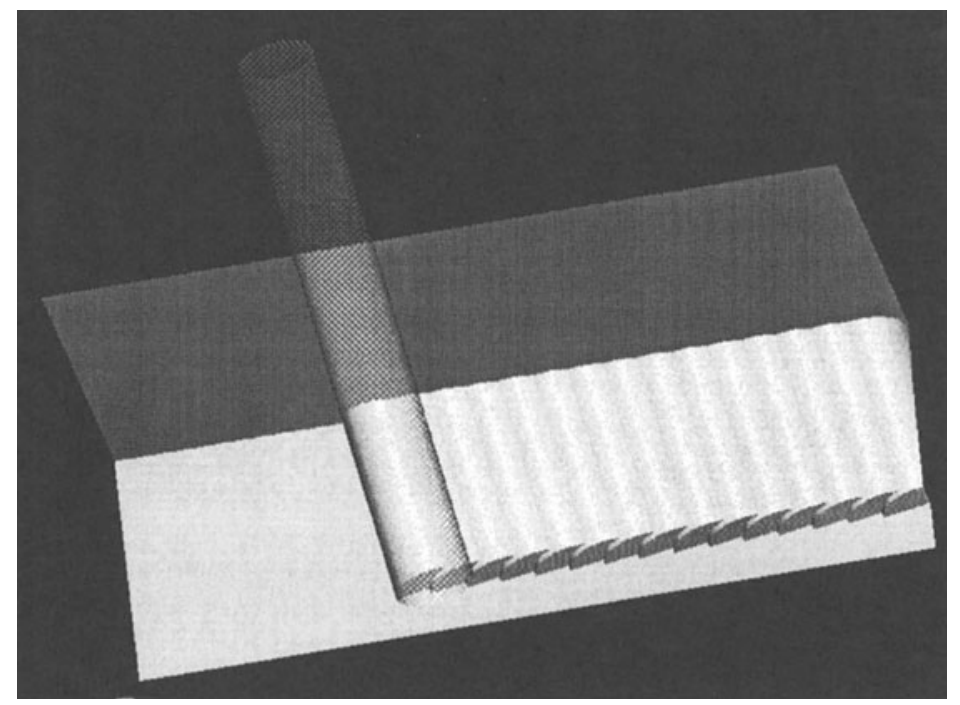

Figure 13. Correct cut depth for indexed 5-axis plunge cutting

Another prerequisite that is related to the max-value of the radial stepover distance is the fact that a particular plunge cut must not cut deeper than the previous cut. Otherwise the tool cuts with the whole end surface, which can lead to complete tool damage. As Figure 13 illustrates, one way to assure that this condition is satisfied, is to tilt the tool axis some degrees in the step over direction. How many degrees the tool axis has to be tilted is the result of a time-consuming try-and-error-process.

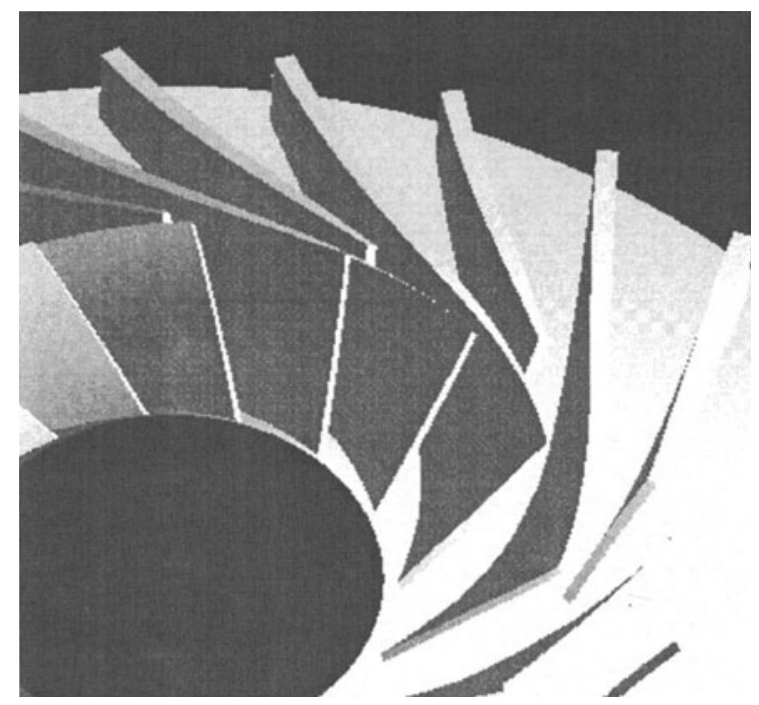

Figure 14. Angle between vane and floor surface 
During the introduction of indexed 5-axis plunge cutting, we said that the tool axis is oriented in the direction of the normal of the floor surface, to minimise the amount of excess material left on the floor surface. This demand can not always be fulfilled. This is the case for the machining of the surface area between the vanes, especially the area near the centre of the runner, where the angle between the vanes and the bottom surface is less than $90^{\circ}$. The tool axis must be oriented in a plane parallel to the side of the vanes, to be able to access the area between the vanes (see figure 14). The angle between the vanes and the floor surface varies from the outside to the inside, so that in this case the orientation of the tool axis has to follow other guides than the normal of the floor surface.

The orientation of the tool axis for simultaneous 5-axis plunge cutting is another parameter that is difficult to determine. The angle between the tool axis and the surface normal of the surface to be machined is near $90^{\circ}$, but as figure 12 illustrates, the angle can never be exactly $90^{\circ}$, in order to avoid either gouging or excess material. To find an optimal orientation of the tool axis, so that the contact point follows the surface to be machined, without gouging the surface, is a time consuming process.

The conclusion of this chapter is, that the problem of optimised tool positioning and orientation for 5-axis-plunge-cutting is not yet solved satisfactorily. It is true that it is possible to generate toolpaths for 5-axis plunge cutting, but the generation process is characterised by much manual work and a good portion of experience. This makes it difficult for not experienced users to adopt the method.

\section{HOW CAN A RESEARCHER CONTRIBUTE TO IMPROVEMENT IN A COMPANY-PROCESS THAT HAS BEEN CONTINOUSLY DEVELOPED BY HIGHLY SKILLED PERSONAL IN DECADES?}

One important difference between a researcher and a consultant is that the researcher should not sell a "solution". For the researcher, in addition to testing theories, possible positive achievement is a result of a process. How was this process, and what was the role of the researcher in this project?

The first critical process of the development project is the introduction of the external researcher to the staff in the company. This was followed up as a separate process by information and a presentation meeting for all staff involved. The most successful factor was maybe the location of researcher near by the operative staff during the whole project. It was a high degree of presence for the researchers in the company during the project period. Participation in "every-day" discussions gave the researchers an accelerated introduction to problems and framework of the particular production environment. Successful communication with both intricate and silly questions was the triggers to reduce the "houseblindness" of the staff. The result of this external view opened the possibility for the staff to look into the problems with new perspectives, and new aspects of implementing improvement in the production process were discovered. It was created a learning arena in addition to order processing. Our understanding of how this interaction should be expressed is shown in figure 15 , and the model show the interaction of formulating theories and hypothesis, develop methods, and the implementation for full scale machining. The research model gives a loopback of experience from the workshop, and the learning arena performs a closed learning circle. 


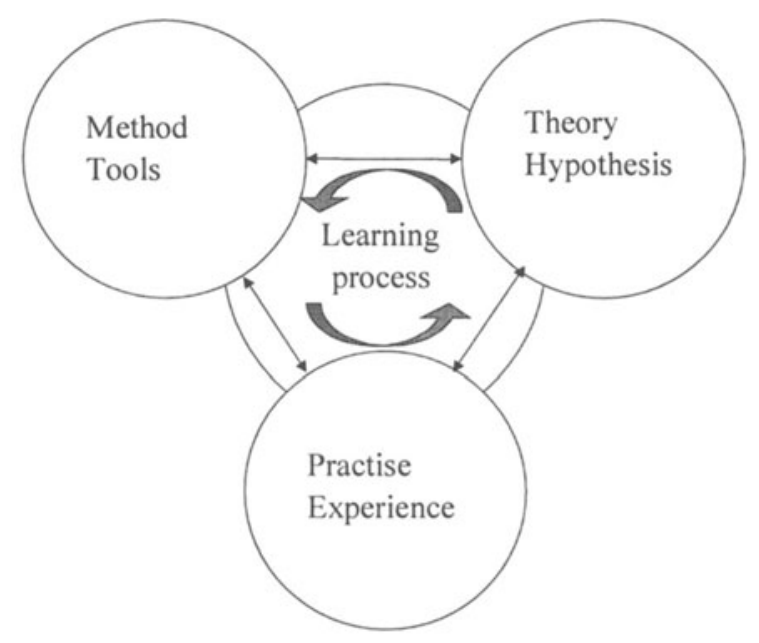

The learning arena

Figure 15. The learning arena as a closed learning circle

\subsection{Time for experiments and the allowance to fail?}

The production of Power Plant Turbines is a very fail critical process. Expensive castings, long lead-time and restricted repair possibilities makes a $100 \%$ error free attitude. Short delivery times push the staff to choose the "safe" solution, even if it is time consuming. Reliability and close follow up by progress measuring ensure a controlled process. It was no allowance to do major experiments, except for everyday improvement in how thing was done. In this relation, the researchers represented an added resource for reflection, experiments, and acted as a network for external contact with development departments at software vendors, tool vendors, other companies and research environments. Together with the focus on vertical communication in the company, introduction of external people formed a multidiscipline arena for joint learning. With this framework it was turning to be more discussions on witch opportunities to work on, more than how to solve problems in every day work. Experience from the project confessed that it was more correct to look at improved methods before starting automation of work operations. This is discussed in the literature as "Double-looplearning" [15]. See also figure 16.

One question is to do tings right (for instance how to program a toolpath), another question is to do the right tings (for instance use plunge cutting in stead of lace machining). It could also be a discussion on who will benefit on what we are doing? It is obviously more motivating to use creativity and innovation in the NC-group to create methods for reduced machining time, instead of a contribution for automation of own work. Most improvement projects in companies do not have only a technical aspect, in this case for example by understanding programming or machining topics, but also an organisational question dealing with different key-factors for empowering a team for releasing a wish for reengineering existing processes. It is a lot of political questions, and the understanding of this situation is expressed as "Triple Loop Learning" [16]: "For whom are we doing it?" 


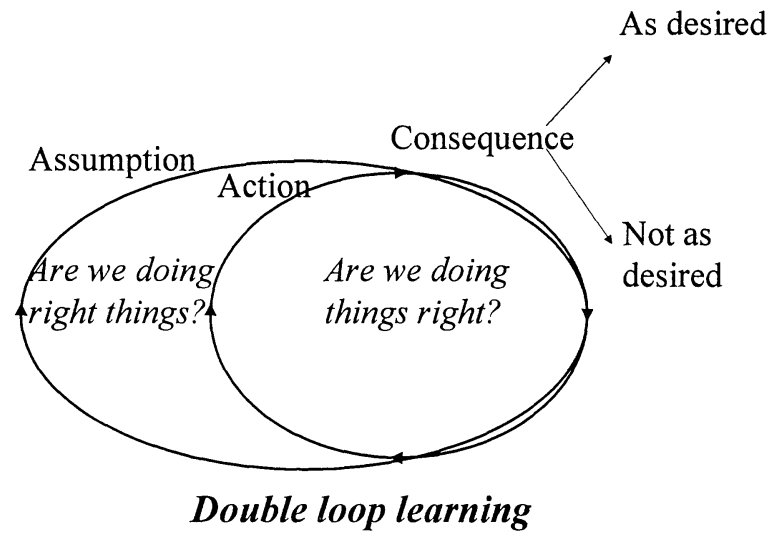

Figure 16. Double loop learning

\subsection{Change resistance as a critical factor?}

The core development team was the NC-programmers. One of the goals for the project was to reduce the time spent on NC-programming with 50\%. One basic idea was to look at the possibility to automate this process by generating parametric NC-programs for machining turbines. Another goal was to reduce machining time with $20 \%$. Machining in 5-axis millingcenters was a bottleneck in the company, and it was a strong need for increased capacity. We now see that conditions and the possibilities for getting good results were better for improving the machining process, than an "automation"-process at the NC-programmers. Results from the improvement measures confess this statement.

\begin{tabular}{|c|c|c|}
\hline $\begin{array}{l}\text { Explicit } \\
\text { knowledge }\end{array}$ & $\begin{array}{l}\text { Formal theory-based } \\
\text { knowledge. } \\
\text { Codified experience } \\
\text { each programmer. }\end{array}$ & $\begin{array}{l}\text { Formal routines, habits } \\
\text { and patterns of collaboratio } \\
\text { Shared methods and } \\
\text { knowledge }\end{array}$ \\
\hline \multirow[t]{2}{*}{$\begin{array}{l}\text { Tacit } \\
\text { knowledge }\end{array}$} & $\begin{array}{l}\text { Experience(not codified) } \\
\text { in individuals: } \\
\text { - crafts and skills } \\
\text { - intuition based on } \\
\text { experience }\end{array}$ & $\begin{array}{l}\text { Informal routines, habits } \\
\text { and patterns of } \\
\text { collaboration } \\
\text { Unwritten organizational } \\
\text { practice in NC-group }\end{array}$ \\
\hline & $\begin{array}{l}\text { Individual } \\
\text { knowledge }\end{array}$ & $\begin{array}{l}\text { Collective } \\
\text { knowledge }\end{array}$ \\
\hline
\end{tabular}

Figure 17. Tacit knowledge in NC-group 


\subsection{High degree of tacit knowledge}

For the group of NC-programmers is was obvious that the result from decades of development has given a lot of individual and organisational knowledge it was impossible for people outside the organisation to compete on. It is known as tacit knowledge (figure 17).

Results from the project contributed to a new standard for fabrication of turbines in this company. This is explicit collective knowledge contributing to the competitive level of this company. But there is still a part of it that is not fully explored. CAD/ CAM systems of today are sophisticated tools. There is no theoretical recipe for how to get good results from the $\mathrm{CAD} / \mathrm{CAM}$ system. To achieve effective 5-axis tool-paths, a lot of experience and skill is involved. During individual experiments, individual methods were developed. It seamed to be impossible to explicitly describe activities NC-programmers used in the CAD/CAM system to achieve adequate results for different machining strategies, different topology of runner and the actual surface behaviour. To make a model of a decision tree seamed to bee to very complex and difficult to achieve.

A complex $\mathrm{CAD} / \mathrm{CAM}$ system gives a high number of alternative methods and combinations of choices to get the final result. To control different functions in the system, there are a large number of different parameters to control both the algorithm for generating tool path, and also to control the behavior of the surfaces and curves. Knowledge in creating functional 5-axis tool-paths was a result of individual experience. It was not possible to get textbook answers for the approach to the individual solution. The resultant machining path is not a key answer, but the human observation and "feeling". The iteration process is shown in figure 18 .

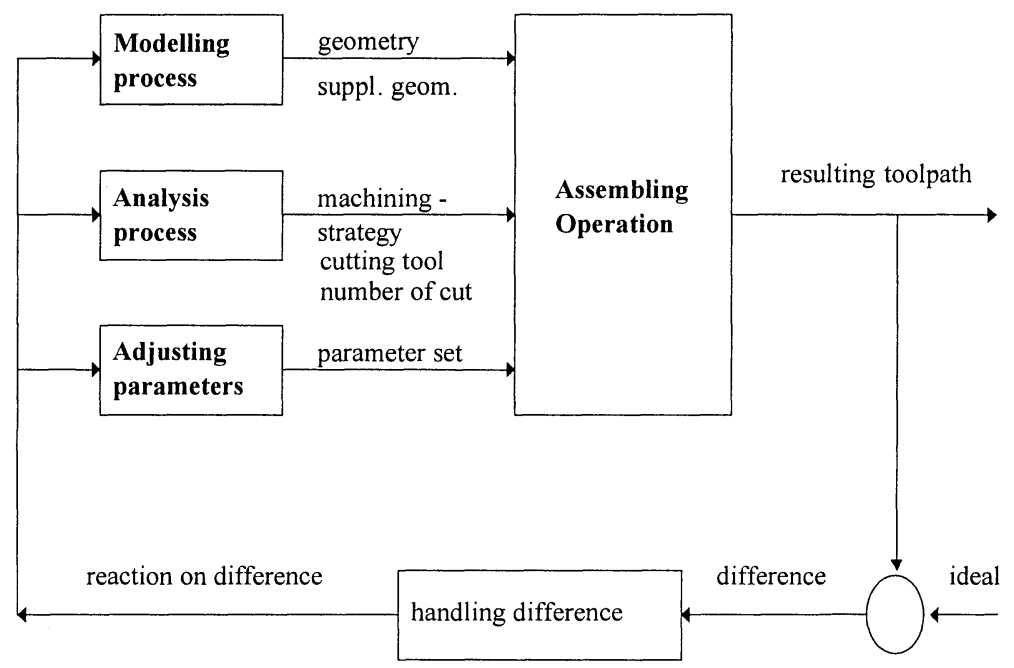

Figure 18. Iteration process in toolpath generation

The individual skill in programming and achievement of good NC-programs is a combination of knowledge in use of different functions and possibilities in the CAD/CAM system, and experience from what is good enough during machining process. It is a high degree of experienced knowledge. Continuous feedback from the workshop over a long time tells the programmer what is correct quality. By nature it is difficult to express this knowledge explicit: It is tacit knowledge. 
Visualisation and simulation system has best practice from a mission of checking and verifying toolpaths. Our understanding of the effects from a visualisation and simulation system is that it should also be considered as possible computer assisted tools for generation of tacit knowledge in controlling complex CAD/CAM systems. Efficient systems and high quality visualisation increase the possibility to speed up learning circle, and the individual programmer's skill in controlling complex systems increase.

\section{CONCLUSIONS}

This paper presented the results of a research project that lead to a quantum leap improvement of the manufacturing of hydropower turbines.

Improved machining strategies, e.g. parallel cut, constant gap strategy, 5-axis plunge cutting, were introduced that resulted in significant reduction of machining time for individual components of a turbine runner. In addition, a new manufacturing process, splitting the geometry of the runner into two halves, was presented.

The paper finishes with reflections about the mechanisms that made the success possible.

\section{ACKNOWLEDGMENTS}

Thank to workers, operators, engineers and managers at Kvaerner Energy a.s for the hospitality and confidence shown during this project. We thank Norwegian Research Council for giving us the opportunity to do the research in this topic. We also thank the software vendors, tool-manufactures and companies that have participated in discussions and brainstorming during this project. At last we will thank our professor Finn Ola Rasch at NTNU for being professional adviser during this project.

\section{REFERENCES}

[1] Blikø I., Köwerich S.: Process Optimised machining of ...., SINTEF Report no STF38 F97224 , 1997 (Restricted, Norwegian)

[2] Kruth J.-P., Klewais P.: Optimisation and Dynamic Adaptation of the Cutter Inclination during FiveAxis Milling of Sculptured Surfaces, CIRP Annals v 43 n 1 1994. p 443-448

[3] Klocke F., Löffler R.: Prozessanalyse bei der Fünfachsen-Fräsbearbeitung, Zeitschrift für Wirtschaftlichen Fabrikbetrieb v 91 n 5 May 1996. p 223-226

[4] Lee Y.-S., Chang T.-C.: Automatic cutter selection for 5-axis sculptured surface machining, International Journal of Production Research v $34 \mathrm{n} 4$ Apr 1996. p 977-998

[5] Rao N., Bedi S., Buchal R.: Implementation of the Principal-Axis Method for Machining of Complex Surfaces, International Journal of Advanced Manufacturing Technology v 11 n 4 1996. p 249-257

[6] Yu Daoyuan, Duan Zhengcheng, Zhuang Xiong, Liu Jinning: Local discretization without tolerance in the CAD/CAM and NC programming of a sculptured surface, Journal of Materials Processing Technology v 57 n 1-2 Feb 1 1996. p 195-200

[7] Cho H.D., Jun Y.T., Yang M.Y.: Five-axis CNC milling for effective machining of sculptured surfaces, International Journal of Production Research v 31 n 11 Nov 1993. p 2559-2573

[8] Li Susan X., Jerard Robert B.: 5-axis machining of sculptured surfaces with a flat-end cutter, Computer Aided Design v 26 n 3 Mar 1994. p 165-178

[9] Li F., Wang X.C., Ghosh S.K., Kong D.Z., Lai T.Q., Wu X.T.: Gouge detection and tool position modification for five-axis NC machining of sculptured surfaces, Journal of Materials Processing Technology v 48 n 1-4 Jan 15 1995. p 739-745

[10] Lee Y.-S., Chang T.-C.: Machined surface error analysis for 5-axis machining, International Journal of Production Research v $34 \mathrm{n} 1$ Jan 1996. p 111-135

[11] Choi B.K., Park J.W., Jun C.S.: Cutter-location data optimisation in 5-axis surface machining, Computer Aided Design v 25 n 6 Jun 1993. p 377-386

[12] Li F., Wang X.C., Ghosh S.K., Kong D.Z., Lai T.Q., Wu X.T.: Tool-path generation for machining sculptured surface, Journal of Materials Processing Technology v 48 n 1-4 Jan 15 1995. p 811-816 
[13] Greenbaum J. and Kyng M.: Design at Work: Cooperative Design of Computer Systems, Lawrence Erlbaum Associates, New Jersey, 1991

[14] Bjerknes G., Ehn P., Kyng M. (eds): Computers and Democracy - a Scandinavian challenge, Aldershot, UK, 1987.

[15] Argyris C., \& Schön D.A.,: A Theory of Action Perspective. Addison-Wesley Publishing Company, USA, 1978

[16] Flood R.L., and Romm N.R,: Diversity Management - Triple Loop Learning. Wiley, England, 1996. 